5 (2), Aralık, 2020

\title{
YABANCI DİL OLARAK TÜRKÇE ÖĞRETIMIINDE TÜRK KÜLTÜR ÖGELERINIIN AKTARIMINA YÖNELİK BİR DURUM ÇALIŞMASI
}

\section{EXAMINATION OF A CASE STUDY FOR THE TRANSFERENCE OF TURKISH CULTURAL ELEMENTS IN TURKISH LANGUAGE TEACHING}

\author{
Araştırma Makalesi
}

\author{
Betül KOPARAN¹ Mehmet CANBULAT ${ }^{2}$ \\ Makale gönderim tarihi: 23.06.2020
}

Makale kabul tarihi: 29.12.2020

\begin{abstract}
$\ddot{O} z$
Günümüzde yabancı dil olarak Türkçe öğretimi, çeşitli ülkelerdeki insanların farklı farklı ihtiyaç ya da sebeplerle Türkiye'ye gelmesi sonucunda birçok farklı kurumda yapılmakta ve bu kurumlarda öğrenim gören yabancı öğrencilerin sayısının her geçen gün arttığı bilinmektedir. Bu durum Türkçeyi, yabancıların öğrendikleri bir dil hâline getirirken aynı zamanda da Türkçenin yabancı dil olarak öğretiminin de önemini ortaya koymaktadır. Bu doğrultuda araştırma, nitel araştırma yöntemlerinden durum çalışmasına göre desenlenmiştir. Nitel araştırma yöntemine uygun olarak doküman analizi, odak grup görüşmesi ve bireysel görüşmeler ile veriler elde edilmiştir. Verilerin analizi, içerik analizi yoluyla yapılmıştır. Araştırmanın sonucunda yabancı öğrenciler Türk kültür ögelerini daha çok sosyal hayat, Türk arkadaşlar ve dizilerden öğrendiklerini bununla beraber ders kitaplarından ve öğretim elemanlarından da bu konuda yararlandıklarını ifade etmişlerdir. Ayrıca ders kitaplarında da Türk kültür ögelerinin yer aldığı fakat daha güncel ve yabancı öğrencilerin ilgi ve ihtiyaçlarına yönelik kültür ögelerinin yer alması gerektiği sonucuna ulaşılmıştır.
\end{abstract}

Anahtar Kelimeler: Yabancı dil öğretimi, Yabancı dil olarak Türkçe öğretimi, dil ve kültür ilişkisi, kültürel etkileşim, kültür aktarım.

\begin{abstract}
Today, teaching Turkish as a foreign language is carried out in many different institutions as a result of people coming to Turkey due to different needs or reasons and it is known that the number of these foreign students increases day by day. This situation makes Turkish a language that foreigners learn and also shows the importance of teaching Turkish as a foreign language. In this context, the research was designed according to the case study, one of the qualitative research methods. Data were obtained through document analysis, focus group interview and individual interviews in accordance with qualitative research methodology. The collected data analyzed through content analysis. As a result of the research, foreign students stated that they learned Turkish cultural elements mostly from "social life, Turkish friends and soap operas". Besides these, they could also benefit from "textbooks and lecturers". In addition, it is concluded that there are Turkish cultural elements in the textbooks, but cultural elements should be included for students' interests and needs and they should be more up to date elements.
\end{abstract}

Keywords: Foreign language teaching, Turkish teaching as a foreign language, language and culture relationship, cultural interaction, culture transfer.

\section{Giriş}

Dil, insanlar arasındaki iletişiminin en temel kaynağını oluşturmaktadır. Dilin bireyler arasındaki duyguları, düşünceleri ve bilgi birikimlerini aktarma işlevinin yanı sıra konuşurları arasında kültürünü, gelenek ve göreneklerini, milli duyuş ve düşüncelerini taşıma işlevi de vardır. Dolayısıyla dil, tek boyutla sınırlandırılamayan çok boyutlu bir olgudur.

\footnotetext{
${ }^{1}$ Arş. Gör., Akdeniz Üniversitesi, Türkçe ve Sosyal Bilimler Eğitimi Bölümü, Antalya/Türkiye ORCID: 0000-00032487-9868, betulkoparan15@gmail.com

2 Prof. Dr., Akdeniz Üniversitesi, Türkçe ve Sosyal Bilimler Eğitimi Bölümü, Antalya/Türkiye ORCID: 0000-00021781-2684, canbulatm@gmail.com
} 
Türkler tarih boyunca birçok medeniyetle ve kültürle iletişim içinde bulunmuş, diğer toplumları kültürüyle etkilediği gibi başka kültürlerden de etkilenmiştir. Ayrıca, Türkiye'nin zaman içinde hem dünyada hem de bulunduğu coğrafi konum içinde göstermiş olduğu etkin rol, sosyal ve politik gelişmeler ile sahip olduğu konum itibarıyla cazip ve önemli bir yatırım alanı olarak görülmektedir. Bu durum neticesinde, yabancı dil olarak Türkçe öğrenimi günümüzde gün geçtikçe artarak ilerleyen bir alan haline gelmiştir (Kurt, Direkci ve Caner, 2018).

Bugün, yabancı dil olarak Türkçe öğretimi çeşitli ülkelerdeki insanların farklı farklı ihtiyaç ya da sebeplerle ülkemize gelmesi sonucunda birçok farklı kurumda yapılmakta ve ülkemize gelen bu yabancı öğrencilerin sayısının her geçen gün arttığı bilinmektedir. Bu durum Türkçeyi, yabancıların öğrendikleri bir dil haline getirirken aynı zamanda da Türkçenin yabancı dil olarak öğretiminin önemini ortaya koymaktadır. Böylesine önemli bir alan olan yabancı dil öğretiminde dikkat edilmesi gereken birçok unsur bulunmaktadır. Bu unsurlardan belki de en önemlilerinden biri dil öğretiminde doğru ve etkili bir kültür öğretiminin gerçekleştirilmesidir. Çünkü tam anlamiyla bir dil öğretiminin gerçekleşmesi için dilin konuşulduğu milletin kültürünün aktarılabilmesi de gerekir. Buna ek olarak, dil aracilığıyla kültür öğretiminin gerçekleşmesi, bireyin o dilin konuşulduğu ülkede olması durumunda daha da kolaylaşır.

Bir kişinin ana dili becerisi geliştikçe, ait olduğu milletin kültürüne hâkimiyeti de artmaktadır. Bu nedenle dil öğretimi, aynı zamanda bir kültür öğretimi olarak da adlandırılabilmektedir. Dildeki her türlü yapı ile anlam arasındaki ilişkinin kültürel bir boyutu vardır (Arslan, 2009).

Dil göstergeler dizgesi olarak tanımlanabilir. Fakat bununla beraber bir kültür ögesi olarak da yer alır. Bu dil ve kültürün birbirleriyle olan ayrılmaz yakınlığından dolayı dil öğrenimi ve öğretiminde kültür ögesini göz ardı etmemek gerekmektedir. Dildeki dizgeler içerisinde yer alan her göstergenin diş dünyada işaret ettiği bir gönderme alanı, bir dış dünya gerçekliği vardır. İşte bu göstergelerin dış dünyada işaret ettikleri gönderme alanı da dilin kültürle ilgili olan kısmıdır. Göstergelerin anlamları da böylece ortaya çıkmaktadır. Göstergelerin edindikleri bu anlamla beraber de kültür ögesi oluşmakta ve dilin anlamsal yapıyı tamamlanmaktadır (Asutay, 2003: 27). Dolayısıyla dilin şekilsel yapısının içindeki anlamsal yapıyı oluşturan öge kültür olarak tanımlanabilir.

Kültür, toplumu oluşturan kişileri bir arada tutan, birbirine bağlayan dil ve haberleşme süreçlerini, sanatlarını, inançlarını, törelerini, hukuk ve yönetim kurumlarını, üretim ve tüketim düzenlerini içine alır (Güvenç, 2002: 14-15). Abacıoğlu (2002: 5) kültürün bir aynası olarak da dili görmüştür.

Her kültürün, ait olduğu topluma dair özelliklerini yansıtan, kendi kimliğini kazandırmasına vesile olan kendine özgü bir dili vardır denilebilir. Bu dil, içinde bulunduğu kültürün diğer toplumların özelliklerinden farklılıklarını, diğer bir deyişle 'ötekilerden olan farkını' ve tarihsel toplumsal tüm birikimlerini içinde barındırır. Bundan dolayı denilebilir ki; dil öğrenmek, o kültürü tanımakla başlar, devam eder ve gelişir (Asutay, 2007: 10). Yabancı bir dili öğrenmeye çalışmak aynı zamanda o kültürün ögelerini de anlamak, öğrenmek istemek ve bunun için çabalamak şeklinde düşünülebilir (Göçer, 2015: 23).

Özdemir (2013), kültür ögelerini bilmeyen bir yabancı öğrencinin, dilin kinayeli, mecazlı ve sanatlı yapısını da bilemeyeceğini, anlayamayacağını ifade etmiştir. Barın (2004) da aynı şekilde günlük yaşantıdan, insanlar arasındaki gündelik ilişkilerden kopuk olan bir dil öğretiminin eksik olacağını hatta ne dili ne de kültürü tam olarak aktaramayacağını belirtmiştir.

Program, öğretim, yönetim ya da değerlendirme olsa da olmasa da eğitim için yapılan tüm şeylerin kalbinde kültür yer almaktadır (Gay, 2014: 9) Şüphe yoktur ki eğitim, sosyo- kültürel bir süreçtir. Bir bireyin eğitim yaşamının anlaşılması için kültürün rolünün de titiz bir şekilde irdelenmesi gerekmektedir (Pai, Adler ve Shadiow, 2006).

Türkçenin yabancı dil olarak öğretimine yönelik yapılan çalışmalara bakıldığında genellikle, bu alanda kullanılan yaklaşım ve yöntemlerin hangileri olduğu, hangi yöntemlerin kullanılması gerektiği ve yöntemlerin faydaları ve zararları (Tezcan, 1990; Hengirmen, 1993; Tosun, 2005; İşcan, 2011; Yaylı ve Yaylı, 2014; Erdem, Gün ve Sever, 2015; Harputoğlu, 2015; Çağlayan Dilber, 2018) ile yabanc1 öğrencilerin dili öğrenirken yaşadıkları sorunlara yönelik çalışmalar (Karababa, 2009; Demirel, 2011; Okatan, 2012; Şahin, 2018) olduğu gözlemlenmiştir. Dil öğretiminde kültür aktarımının yapılması 
gerektiğine yer veren çalı̧̧malar da yapılmıştır (Polat, 1990; Tapan, 1990; Kramsch, 1993; Tseng, 2002; Er, 2006; Bölükbaş ve Keskin, 2010; Demir ve Açık, 2011; Kırkkılıç ve Sevim, 2012; Okur ve Keskin, 2013; Kutlu, 2015; Memiş, 2016; İşcan ve Yassıtaş, 2018).

Yapılan çalışmalar sonucunda, yabancılara Türkçe öğreten öğretim elemanlarının ise bu alandaki eğitimlerinin genel olarak yetersiz olduğu ve süreç içinde meslekî deneyimleriyle konu hakkında derinleştikleri görülmüş̧ür (Karababa, 2009; Kuş̧̧u, 2013; Mete ve Gürsoy, 2013). Yabancılara Türkçe öğretiminde kendi kültürünü bilen, kültürünün özelliklerine hâkim olan ve bunu ders sürecinde doğru ve etkili bir biçimde aktarabilen öğreticiler, öğrenmeyi kalıcı bir hale getirecek ve dersin etkili ve renkli bir şekilde geçmesine imkân sağlayacaktır (Saygılı ve Kana, 2018: 1044).

YÖK-TEZ veri tabanında "yabancı dil olarak Türkçe öğretiminde kültür aktarımı ve kültürel etkileşim” anahtar kelimeleriyle yapılanan taramada 2010-2020 yılları arasında yapılan çalışmalarda yabancı dil olarak Türkçe öğretimi ders kitaplarında bulunan kültür ögelerinin incelenmesine yönelik birçok çalışmanın olduğu görülmüştür. Ancak kültür aktarımının Yabancılara Türkçe öğretiminde kullanılan ders kitapları, öğretim elemanları ve yabancı öğrenciler bağlamında ele alınmasına dair bütünleyici bir çalışma olmadığı tespit edilmiştir. Bu çalışmaya literatürdeki bu eksikliğin giderilmesi için gerek duyulmuştur. Çalışmada yabancılara Türkçe öğretiminde görev yapmakta olan öğretim elemanları, yabancı öğrenciler ve ders kitaplarının Türk kültür ögelerinin aktarımındaki yerleri ve durumları bütüncül bir şekilde resmedilmeye çalışılacaktır.

Çalışmada yabancı dil öğretiminde, kültür öğretiminin öneminden yola çıkılarak ilk olarak Akdeniz Üniversitesi Türkçe Öğretimi Uygulama ve Araştırma Merkezinde yabancı dil olarak Türkçe öğretiminde kullanılan ders kitaplarında Türk kültürüne ait ögeler belirli ölçütlere göre incelenmiştir. Bu ders kitaplarında bulgulanan Türk kültür ögelerinden hareketle yine Akdeniz Üniversitesi Türkçe Öğretimi Uygulama ve Araştırma Merkezinde görev yapmakta olan öğretim görevlilerinin ve öğrenim görmekte olan yabancı öğrencilerin Türk kültürü hakkındaki görüşlerine başvurulmuştur.

\section{Araştırmanın Amacı ve Problemleri}

Yabancı dil olarak Türkçe öğretiminde Türk kültür ögelerinin aktarımı nasıl gerçekleşmektedir? Bu problem cümlesinden hareketle, araştırmanın alt problemleri şu şekildedir:

\section{Alt Problemler}

1. Yabancı dil olarak Türkçe öğrenen öğrencilerin, Türk kültür ögelerinin aktarımı hakkındaki görüşleri nelerdir?

2. Yabancı dil olarak Türkçe öğretiminde Türk kültür ögelerinin aktarımına ilişkin öğretim elemanlarının görüşleri nelerdir?

3. Yabancı dil olarak Türkçe öğretiminde kullanılan ders kitaplarında, kültürel ögeler nasıl yer almaktadir?

\section{Araştırma Deseni}

\section{Yöntem}

Bu çalışma sosyal bilimlerde yaygın olarak kullanılan nitel araştırma yöntemlerinden durum çalışması desenine göre tasarlanmıştır. Nitel araştırmalardan biri olan durum çalışması, bir ya da birden çok olayın, durumun derinlemesine ifade edilmesi, araştırılması, incelenmesi ve yorumlanması olarak açıklanır (McMillan ve Schumacher, 2006). Bu bağlamda araştırmacının durum çalışmalarında en önemli hedefi bir ya da birden çok durumu ele alırken tanımlama yapmasıdır. (Christensen, Johnson ve Turner, 2011). Bu nedenle durum çalışması deseni, bu çalışmanın incelenmesinde uygun desen olarak belirlenmiştir. 


\section{Araştırma Materyali ve Çalışma Grubu}

Çalışma, 2018-2019 yılında Akdeniz Üniversitesi Türkçe Öğretimi Uygulama ve Araştırma Merkezi'nde (TÖMER) yabancı dil olarak Türkçe öğrenmekte olan yabancı öğrenciler (n-43) ve eğitim vermekte olan öğretim elemanları $(n=10)$ üzerinde amaçlı örneklem yöntemlerinden kolay ulaşılabilir örneklem tekniği ile seçilen toplam 53 kişi üzerinde yapılmıştır. Ayrıca bir diğer veri kaynağı olarak İstanbul Yabancılar İçin Türkçe öğretim seti A1-A2 (Temel), B1-B2 (Orta) ve C1/+ (İleri) olmak üzere beş kitapta çalışmanın amacı doğrultusunda, Türk kültür ögeleri bakımından Avrupa Konseyi'nin (Council of Europe) 2013 yılında yayınladığı bir bildirgeyle hazırlanan ve öğretilen yabancı dile ait sosyal ve kültürel bilgilerin de verilmesi gerektiğini detaylı olarak belirtilen bir takım ölçütlere (günlük yaşam, yaşam koşulları, kişiler arası ilişkiler, değerler, inançlar ve tutumlar, beden dili, sosyal gelenekler, geleneksel davranışlar) göre incelemeler yapılmıştır.

\section{Verilerin Toplanması}

Durum çalışmalarında veri toplama aracının fazla olması önemlidir. Böylece çalışmanın geçerlik ve güvenirliği artmış sayılmaktadır (Yin, 1984; Hartley, 1995). Bu durum göz önünde bulundurularak, çalışmada birden fazla veri toplama aracı kullanılmıştır. Çalışmanın verileri uzman görüşleri, öğrenci görüşleri ve doküman incelemesi olmak üzere üç yolla toplanmıştır.

Çalışma yarı yapılandırılmış odak grup görüşmesi yapılan yabancı öğrenciler (sekizerli dört grup olmak üzere toplamda otuz iki katılımcı), yarı yapılandırılmış bireysel görüşme yapılan yabancı öğrenciler (on bir katılımc1) ve yarı yapılandırılmış bireysel görüşme yürütülerek görüşleri alınan öğretim elemanları (on katılımcı) olmak üzere üç farklı çalışma grubu ile yürütülmüşsür. Araştırma sürecinde elde edilen veriler not alma tekniği ve ses kayıt cihazı yoluyla toplanmıştır. Daha sonra toplanan bu veriler düzenlenip yaziya geçirilmiştir.

\section{Verilerin Analizi}

Araştırmanın amacına uygun olarak sorular hazırlanmış ve gerekli izinler alınarak çalışma grubunu oluşturan katılımcılarla görüşmeler gerçekleştirilmiştir. Yazıya geçirilen metinler iki kez kontrol edilip düzenlenerek kopyası çıkarılmış, kodlanmış, özetlenmiş ve yorumlanmıştır. Bu çözümlemeler süreç içinde Türkçe Eğitimi alanında uzman üç farklı araştırmacı tarafından daha kontrol edilmiştir.

\section{Araştırmanın Geçerlik ve Güvenirliği}

Araştırmadan elde edilen görüşmelerin iç güvenirliği için bulgular hiç yorum yapılmadan olduğu gibi verilmiş, araştırmacı ve nitel araştırma konusunda deneyimli Türkçe Eğitimi alanında uzman bir öğretim üyesi ve bir yüksek lisans öğrencisi olmak üzere iki kişi tarafından ayrı ayrı kodlamalar yapılmıştır. Elde edilen kodlamalar karşılaştırılarak, ortak kodlara ulaşılmıştır. Kodlayıcılar arasında Kappa değeri (tutarlık oranı) hesaplanmıştır. Değerlendiriciler arasında \%88,5 değerinde bir uyum olduğu görülmüştür. Bu hesaplanan tutarlık oranı sonucunda araştırmacılar arasında mükemmel bir uyum olduğu ve çalışmanın kodlarının güvenilir olduğu sonucuna ulaşılmıştır.

\section{Bulgular}

$\mathrm{Bu}$ bölümde görüşme formlarında yer alan sorulara verilen yanıtlar ve ders kitaplarının incelenmesi doğrultusunda ortaya çıkan bulgulara yer verilmiştir. Bulgular, yabancı öğrenciler, öğretim elemanları ile gerçekleştirilen görüşmeler ve ders kitaplarının incelemesi olmak üzere üç ana başlık altında sunulmuştur. Veriler her bir bölümün altında, araştırma sorularındaki gibi alt araştırma sorularına yönelik bulgularla sunulmaya çalışılmıştır. Tablolar halinde sunulan veriler frekans değerleri üzerinden yorumlanmış ve katılımcı görüşlerinden örneklere yer verilmiştir. 


\section{Yabancı Öğrencilerle Gerçekleştirilen Görüşmeler Sonucu Ortaya Çıkan Bulgular}

Bu bölümde çalışma grubu kısmında bahsedilen kırk üç yabancı öğrenci ile gerçekleştirilen görüşmeler sonucu ortaya çıkan bulgulara yer verilmiştir.

\subsection{Yabancı Öğrencilerin Kültür Hakkındaki Görüşleri}

Uygulama ve değerlendirme sürecinden sonra katılımcılara kültür hakkındaki görüşleri ile ilgili bir soru sorulmuş ve ortaya çıkan görüşler Tablo 1.1.'de sunulmuştur:

Tablo 1.1. Yabancı Öğrencilerin Kültür Hakkındaki Görüşleri

\begin{tabular}{ll}
\hline Görüşler & f \\
\hline Dil & 7 \\
Yaşam Biçimi & 9 \\
Tarih & 1 \\
Edebiyat & 1 \\
Yiyecekler- İçecekler & 3 \\
Davranış Biçimi & 7 \\
Gelenek- Görenek & 6 \\
Kurallar & 3 \\
Eylemler & 1 \\
\hline Toplam & $\mathbf{4 3}$
\end{tabular}

Tablo 1.1. incelendiğinde; yabancı öğrencilerin kültür hakkındaki görüşlerine yönelik en fazla öne çıkarılan görüş "yaşam biçimi" ifadesidir. Bu görüşü "dil, davranış biçimi, gelenek- görenek, kurallar, yiyecekiçecekler" gibi görüşler izlemektedir. Bu ifadeleri desteklemesi bakımından katılımcı görüşlerinden örneklere aşağıda yer verilmiştir:

"Bence kültür demek dil öğrenmek benim için. Ĕğer sen dil öğrenirsen demek ki sen başka ülkelerin hakkında biliyorsun." (Ö, 15),

"Ben kültür derken yani benim aklım kültür derken insanlar nasıl yaşıyorlar? Benim aklıma geliyor. Nasıl yaşıyorlar? İnsanlar nasıl yaşıyorlar öğrenmek için önce insanların dilini öğrenmek gerekiyor." (Ö, 3),

" Benim için kültür demek tarih demek. Çünkü bir ülkenin kültürü yok. Demek ki tarihi yok. Kültür geçmiş demek benim için. Tarih demek. Bir ülke kültür yok tarih yok benim için."(Ö, 8).

\subsection{Yabancı Öğrencilerin Türk Kültürr Ögelerine İlişkin Bilgi Kaynakları Hakkındaki Görüşleri}

Yabancı öğrencilerin Türk kültür ögelerine ilişkin bilgi kaynakları hakkındaki görüşleri aşağıda Tablo 1.2' de sunulmuştur: 
Tablo 1.2. Yabancı Öğrencilerin Türk Kültür Ögelerine İlişkin Bilgi Kaynakları Hakkındaki Görüşleri

\begin{tabular}{ll}
\hline Görüşler & f \\
\hline Sosyal Hayat & 9 \\
Türk Arkadaşlar & 8 \\
Ders Kitapları & 8 \\
Öğretmenler & 6 \\
Kitaplar ve Dergiler & 5 \\
Dizi, Film ve Tiyatro Oyunları & 4 \\
Videolar & 2 \\
İnternet & 2 \\
Televizyon & 1 \\
Geziler & 1 \\
\hline Toplam & $\mathbf{4 6}$
\end{tabular}

Tablo 1.2. incelendiğinde; yabancı öğrencilerin Türk kültür ögelerine ilişkin bilgi kaynakları hakkındaki görüşlerine yönelik on farklı kategoriye ulaşılmıştır. Bu kategoriler sıklık değerleri açısından sırasıyla şu şekildedir: "sosyal hayat" , (f=9); "Türk arkadaşlar" , $(\mathrm{f}=8)$; "ders kitapları" , $(\mathrm{f}=8)$; "öğretmenler", $(\mathrm{f}=6)$; "kitaplar ve dergiler", ( $\mathrm{f}=5)$; "dizi, film ve tiyatro oyunlar" , $(\mathrm{f}=4)$; "videolar", $(\mathrm{f}=2)$; "internet", $(\mathrm{f}=2)$; "televizyon", ( $\mathrm{f}=1)$ ve "geziler", $(\mathrm{f}=1)$. Bu görüşlerden bazıları aşağıda yer alan ifadelerle örneklendirilmiştir:

“Mesela benim için Türkçe öğreniyorsan eğer Türkiye'de yaşıyorsan daha iyi olacak. Çünkü o zaman hayal edelim. Ben Türkçe öğreniyorum ama Tunus'ta sizin kültürünüzü hiç bilmiyorum. Hiçbir şey öğrenmeyeceğim. Kültürü sokaktan öğrenebiliriz. Dil bilgisini kitaptan öğrenebiliriz. İkisi paralel şekilde gidiyor. Tamamlıyor birbirini."( Ö,6),

"Ben mesela bir şeyi anlamadı̆̆ımda arkadaşımı arıyorum. Mesela dünkü grameri anlamadım. Arkadaşımı aradım. O hemen geldi. Çünkü çok yardımsever bir insandır ve bana grameri anlattı. Sokak dilinde anlattı ve tabii ki evet yani normal şekilde anlattı. O kadar yani. Konuştukça ve pratik yaptıkça daha çok öğreniyoruz. Arkadaşım Türk'tü." (Ö, 17),

“Ders kitapları pek çok şey Türkiye'nin kültürü hakkında gösteriyor bize. Hayat, normal hayat, sosyal hayat, günlük hayat, kültür, evlilik, komşuluk..." (Ö, 5).

\subsection{Yabancı Öğrencilerin Ders Kitaplarında Yer Alan Türk Kültür Ögeleri Hakkındaki Görüşleri}

Tablo 1.3.' te yabancı öğrencilerin ders kitaplarında yer alan Türk kültür ögeleri hakkındaki görüşlerine yer verilmiştir:

Tablo 1.3. Yabancı Öğrencilerin Ders Kitaplarında Yer Alan Türk Kültür Ögeleri Hakkındaki Görrüsleri

\begin{tabular}{ll}
\hline Görüşler & f \\
\hline Gelenek- Görenekler & 5 \\
Yiyecek ve İçecekler & 4 \\
\hline
\end{tabular}




\begin{tabular}{|c|c|}
\hline Yetersiz Olduğu & 4 \\
\hline Tarih & 3 \\
\hline Halk Edebiyatı & 3 \\
\hline Batıl İnançlar & 3 \\
\hline Din & 2 \\
\hline İnsan İlişkileri & 2 \\
\hline Önemli kişiler & 2 \\
\hline Şehirler & 2 \\
\hline Toplam & 30 \\
\hline \multicolumn{2}{|c|}{ 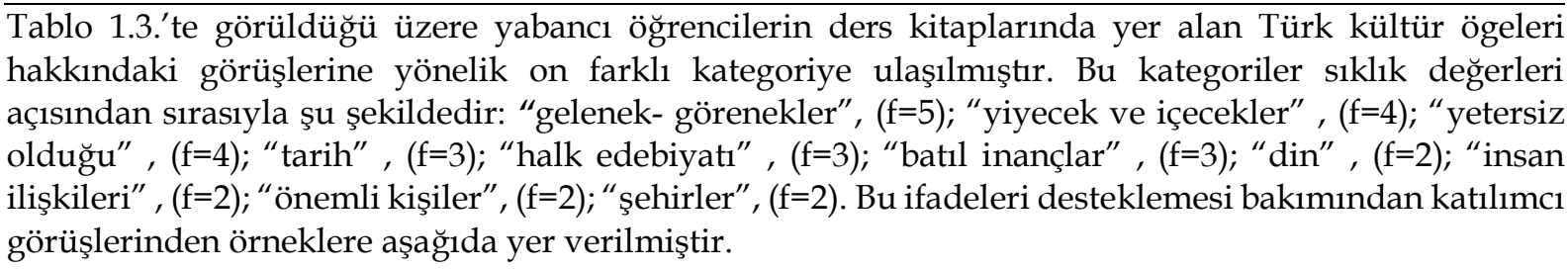 } \\
\hline \multicolumn{2}{|c|}{$\begin{array}{l}\text { "Evet karşılaştık misafir ağırlama vardı. Misafir ağırlama adetleri öğrendik. Mesela haremlik, selamlı öğrendik. } \\
\text { Onları ögrendik. Başka ne vardı? Komşulukla ilgili şeyleri öğrendim. Komşulukla alakalı şeyleri. Aile, çekirdek } \\
\text { aile, geniş aile var Türkiye'de. Önceden bilmiyordum. Onları öğrendim. Siftahi yapmak. Yani yere para atmak. } \\
\text { Kitapta görmüşüm. Batıl inançlar hakkında bunula ilgili bir şey vardı." (Ö, 3), }\end{array}$} \\
\hline \multicolumn{2}{|c|}{$\begin{array}{l}\text { "İlk kitaplardan konukseverlĭ̈i öğrendim. Mesela bir Türk evine misafir ediyorsa, seni ilk önce ayakkabıların } \\
\text { çkartıyorsun o sana başka bir terlik veriyor" (Ö, 9), }\end{array}$} \\
\hline \multicolumn{2}{|c|}{$\begin{array}{l}\text { "Kitapta sadece çok dil bilgisi var. Kitapta kültürel bir şey görmedim. Kültür kitapta görmedim ama hayatta } \\
\text { gördüm." (Ö, 1), }\end{array}$} \\
\hline \multicolumn{2}{|c|}{$\begin{array}{l}\text { “Ders kitaplarından, Türk yemek, Türk yemekleri öğrendim. Gelmeden önce hiç bilmiyordum. Şimdi mesela çok } \\
\text { yemekler, biliyorum. Mesela lahmacun döner, şiş, pide... Hepsini şimdi gelince öğrendim, beğendim. Hepsini çok } \\
\text { seviyorum.” (Ö, 11). }\end{array}$} \\
\hline \multicolumn{2}{|c|}{$\begin{array}{l}\text { 1.4. Yabancı Öğrencilerin Türk Kültürüyle İlgili Daha Çok Bilgi Sahibi Olmak } \\
\text { İstedikleri Türk Kültür Ögelerine İlişkin Görüşleri }\end{array}$} \\
\hline \multicolumn{2}{|c|}{$\begin{array}{l}\text { Yabancı öğrencilerin Türk kültürüyle ilgili daha çok bilgi sahibi olmak istedikleri Türk kültür } \\
\text { ögelerine ilişkin görüşler aşağıda Tablo } 1.4^{\prime} \text { te sunulmuştur: }\end{array}$} \\
\hline \multicolumn{2}{|c|}{$\begin{array}{l}\text { Tablo 1.4. Yabancı Öğrencilerin Türk Kültürüyle İlgili Daha Çok Bilgi Sahibi Olmak İstedikleri Türk Kültür } \\
\text { Ögelerine İlişkin Görüşleri }\end{array}$} \\
\hline Görüsşler & f \\
\hline Tarih & 15 \\
\hline Farklı Çevre ve Yerler & 8 \\
\hline Yiyecekler- İçecekler & 4 \\
\hline Sanat & 3 \\
\hline Türkiye'nin Geleceği & 2 \\
\hline
\end{tabular}




\begin{tabular}{|c|c|}
\hline Dil ile İlgili Konular & 1 \\
\hline Ekonomi & 1 \\
\hline Toplam & 34 \\
\hline \multicolumn{2}{|c|}{ 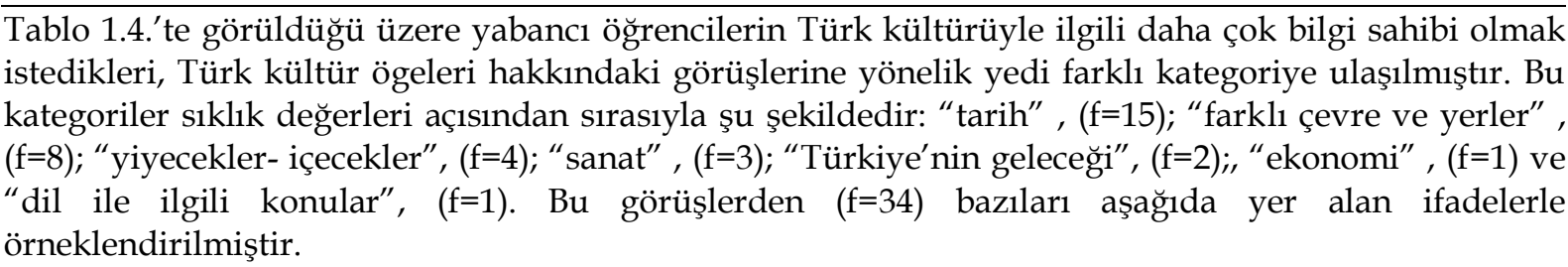 } \\
\hline
\end{tabular}

"Kitaptaki kültür ögeleri yeterli değil. Tarihi konuların fazla yer almasını isterdim." (Ö, 3),

“Osmanlı'yı Harem kültürünü öğrenmek isterdim. Biraz daha bilmek için yani bilgi için. Çünkü dünya yani insanlar konuşuyor hep Osmanlı zamanı Osmanlı zamanı. Her yerde Osmanlı zamanı ismi var. Ben de daha çok bilgi yani okuldan kalan yüzde elliyi öğrenmek istiyorum yani." $(O ̈, 4)$

"Benim bilmek istediğim şey Türkiye'de köyde insanlar nasıl yaşıyor. Bunu merak ediyorum. Ben o köyde yaşıyorlar ya. Ben hiçbir bilgi duymadım." (Ö, 11)

\section{2. Ö̆̆retim Elemanlarıyla Gerçekleştirilen Görüşmeler Sonucu Ortaya Çıkan Bulgular}

Bu bölümde çalışma grubu kısmında bahsedilen on öğretim elemanı ile gerçekleştirilen görüşmeler sonucu ortaya çıkan bulgulara yer verilmiştir.

\subsection{Kültür Aktarımı Hakkındaki Öğretim Elemanı Görüşlerine Yönelik Bulgular}

Tablo 2.1.'de öğretim elemanlarının "kültür aktarımı" konusundaki düşüncelerine yer verilmiştir. Bu araştırma sorusuna ilişkin görüşler aşağıda Tablo 2.1.'de sunulmuştur:

Tablo 2.1. Kültür Aktarımı Hakkındaki Öğretim Elemanı Görüşleri

\begin{tabular}{ll}
\hline Görüşler & f \\
\hline Milli Kültür Unsurlarının Nesilden Nesil Taşınması & 2 \\
Gelenek-Göreneklerin Aktarımı & 4 \\
Dil Öğretiminde Olmazsa Olmaz Unsur & 1 \\
Ön yargıları Yıkan Bir Unsur & 1 \\
Farklı Kültürlerin Kesişmesini Sağlayan Bir Unsur & 1
\end{tabular}

\section{Toplam}

9

Tablo 2.1.'de görüldüğüu üzere kültür aktarımı hakkındaki öğretim elemanı görüşlerine yönelik beş farklı kategoriye ulaşılmıştır. Bu kategoriler sıklık değerleri açısından sırasıyla şu şekildedir: "gelenekgöreneklerin aktarımı", $(f=4)$; "milli kültür unsurlarının nesilden nesile taşınması" , $(f=2)$; "dil öğretiminde olmazsa olmaz unsur", $(\mathrm{f}=1)$; "ön yargıları yıkan bir unsur", $(f=1)$; "farklı kültürlerin kesişmesini sağlayan bir unsur", $(f=1)$. Bu görüşlerden $(f=9)$ bazıları aşağıda yer alan ifadelerle örneklendirilmiştir. Bu ifadeleri desteklemesi bakımından katılımcı görüşlerinden örneklere aşağıda yer verilmiştir:

"Kültür aktarımı yabancılara Türkçe öğretiminde çok önemlidir. Kültür aktarımı toplumumuzun geleneklerini, yaşayış biçimini aktarmaktır. Bu da dil aracılığıyla yapılır." (ÖE,4), 
"Kültür aktarımı yabancı dil öğretiminde olmazsa olmazdır. İki kavram birbirinden ayrılamaz. Öğretmen olarak siz, yabancı dil öğretirken kültürden bahsetmek istemeseniz bile bu imkânsızdır. Yoksa "tatl yiyelim tatl konuşalım" veya "kahvenin kırk yıl hatırı" olduğunu anlatmadan dil öğretmeye çalışır bulursunuz kendinizi ya da "abla" dendiğinde dönüp bakmaz." (ÖE,5),

"Kültür aktarımı, bir toplumda var olan kültürel değerlerin ileriki kuşaklara nesilden nesile taşınması demektir. Bu kültürel değerler dini inançlar, gelenek-görenekler, milli duygular, birlik ve beraberlik isteği, ahlak kurallan gibi durumlar bir millete ait milli kültür unsurlarn olarak kabul edilir. Bunlarm her birinin birey tarafindan bilinmesi gerekirken aynı zamanda korunarak bizatihi geliştirilmesi de gerekmektedir. Bu sayede milli kültür ögeleri gelecek nesillere, kuşaklara aktarılabilir. Bunun için biz öğretmenlere büyük payeler düşmektedir." (ÖE,1).

\subsection{Türk Kültür Ögelerinin Aktarımında Kullanılan Bilgi Kaynaklarına İlişkin Öğretim Elemanı Görüşleri}

Çalışmanın bu bölümünde, “Türk kültür ögelerinin aktarımında kullanılan bilgi kaynaklarına ilişkin öğretim elemanı görüşlerine" yer verilmiştir. Bu araştırma sorusuyla ilgili görüşler sunan öğretim elemanlarından elde edilen verilere dair içerik analizi sonucu Tablo 2.2.'de gösterilmiştir:

Tablo 2.2. Türk Kültür Ögelerinin Aktarımında Kullanılan Bilgi Kaynaklarına İlişkin Öğretim Elemanı Görüşleri

\begin{tabular}{ll}
\hline Görüşler & f \\
\hline Video ve Ses Kayıtları & 7 \\
Kitaplar & 5 \\
Görseller & 2 \\
Diziler ve Filmler & 2 \\
Diğer Farklı Kaynaklar & 2 \\
Geziler & 1 \\
Sözlükler & 1 \\
\hline Toplam & $\mathbf{2 0}$
\end{tabular}

Tablo 2.2.'de görüldüğü gibi Türk kültür ögelerinin aktarımında kullanılan bilgi kaynaklarına ilişkin öğretim elemanlarının görüşleri yedi kategori etrafında toplanmıştır. Araştırmaya katılan öğretim elemanlarından yedisi "video ve ses kayıtlarını", $(\mathrm{f}=7)$; beşi "kitapları" ( $\mathrm{f}=5)$; katılımcılardan ikişer kişi de "görseller", $(\mathrm{f}=2)$; "diziler ve filmler", $(\mathrm{f}=2)$; "diğer kaynakları" ( $\mathrm{f}=2)$ ve birer katılımc da“"gezileri", $(\mathrm{f}=1)$ ve "sözlükleri", $(\mathrm{f}=1)$ kültür ögelerinin aktarımında kullanılan bilgi kaynakları olduğuna yönelik görüş bildirmiştir. Bu konuya ilişkin öğretim elemanlarından bazılarına ait örnekler aşağıda sunulmuştur:

"Yararlandığım kitaplar hatta sözlükler var. Özellikle Türk soylu öğrenciler için Atasözü, Deyimler Sözlüğü, Türk soylu olmayan öğrenciler için Meyve-Sebzeler-Besinler Sözlüğ̈̈nden, Resimli Türkçe Sözlük, Eş Anlamlı Kelimeler, Zıt Anlamlı Kelimeler Sözlüğünden, Dinler tarihi, Ülkeler tarihi kitaplarından yararlanıyorum." $(O ̈ E, 1)$,

"Diziler çok izleniyor. Hatta bazıları bizim benim girdiğim sımıfta konuşma düzeyleri yüksek. Dedim "nasıl bu kadar geliştirebildin?". Çünkü belli bir yere kadar aktarabiliyoruz dili biz. Belli bir yerden sonra onlarm da üzerlerine katmaları gerekiyor. Dedikleri şey "hocam biz daha çok film izledik, dizi izledik." Sevdikleri diziler var. Onlar yoluyla aktarım yapilyor." (ÖE,2),

"Halkiyat olması sebebiyle ve edebiyat olması yönüyle de genel olarak kültür aktarımı yapmamız, sözlü olarak, görsele, videoya dayandırarak daha kolay oluyor. Kız isteme merasimiyle alakalı bir video izlettim. Gelirken çiçek 
çikolata getirmesinden, kahve ikramından görsel ve işitsel materyallerle destekleyerek kültür aktarımı yapmayı amaçliyoruz." (ÖE,8).

\subsection{Ders Kitaplarında Yer Alan Türk Kültür Ögeleri Hakkındaki Öğretim Elemanı Görüsslerine Yönelik Bulgular}

Tablo 2.3.'te öğretim elemanlarının “ders kitaplarında yer alan Türk kültür ögeleri” konuşunki düşüncelerine yer verilmiştir. Bu araştırma sorusuna ilişkin görüşleri aşağıda Tablo 2.3.'te sunulmuştur:

Tablo 2.3. Ders Kitaplarında Yer Alan Türk Kültür Ögeleri Hakkındaki Öğretim Elemanı

\begin{tabular}{ll}
\hline Görüşler & f \\
\hline \multicolumn{1}{c}{ Olumlu Yönleri } & \\
\hline İngilizce Açıklamaların Olması & 1 \\
Kültür ile İlgili Ünitelerin Olması & 1 \\
Türk Kültürü ile İlgili Örneklerin Olması & 1 \\
Ünitelerin Dengeli Dağılmış Olması & 1 \\
\hline
\end{tabular}

\begin{tabular}{ll}
\hline \multicolumn{1}{c}{ Olumsuz Yönleri } \\
\hline Türk Edebiyatı Kaynakları Açısından Yetersiz Olması & 5 \\
Konu Dağılımı ve Konulara Yer Verme Miktarının Dengeli & 5 \\
Olmaması & \\
Diğer Sorunlar & 5 \\
Kaynak Sayısı Açısından Yetersiz Olması & 3 \\
Türk Kültür Ögelerinin Detaylı Verilmemesi & 3 \\
\hline Toplam & $\mathbf{2 5}$
\end{tabular}

Tablo 2.3.'te görüldüğü gibi ders kitaplarında yer alan Türk kültür ögeleri hakkındaki öğretim elemanı görüşlerine yönelik beşi olumsuz, dördü de olumlu olmak üzere toplamda dokuz kategori oluşturulmuştur. Bu kategoriler sıklık değerleri açısından sırasıyla şu şekildedir: "konu dağılımı ve konulara yer verme miktarının dengeli olmaması", $(\mathrm{f}=5)$; “Türk edebiyatı kaynakları açısından yetersiz olması", ( $\mathrm{f}=5)$; "diğer sorunlar", $(\mathrm{f}=5)$; "Türk kültür ögelerinin detaylı verilmemesi" (f=3); "kaynak sayısı açısından yetersiz olması", $(\mathrm{f}=3)$; "İngilizce açıklamaların da Türkçe açılamalarla birlikte olması", $(\mathrm{f}=1)$; "kültür ile ilgili ünitelerin olması", $(\mathrm{f}=1)$; “Türk kültürü ile ilgili örneklerin olması", $(\mathrm{f}=1)$ ve "ünitelerin dengeli dağılmış olması", $(\mathrm{f}=5)$. Öğretim elemanlarını bu soruya verdikleri yanıtlardan bazıları aşağıda yer alan ifadelerle örneklendirilmiştir:

"Burada şöyle bir farklılık da göze çarpıyor. Bir eğitim setinde yer alan kültürel değerler diğer sette yer almıyor ya da tam tersi bir durum söz konusu. Özellikle bazı konularda detaya inilememesi, görsel ve işitsel malzemelerle yeteri kadar desteklenmemesi metinlerin anlaşılmasını güçleştirmektedir."(ÖE, 3),

“Ünlü Türk kadınlarl, Türk bilim adamları, Türk halk edebiyatından bilgi, örneğin Dede Korkut hakkında hiçbir bilgi yok. Kitaplara VCD'ler, DVD'ler eklenmeli. Görüntülü olarak da eğitim verilmeli. Müziklerimizden örnekler kitaplara eklenmeli."(ÖE, 5),

Alana yeni başladıysanız bir tecrübeniz yoksa kitap ne veriyor size? Ben diğer kitaplardan da yararlanarak belli bir birikime ulaştığım için nerede ne vereceğimi bilebiliyorum. Eğer kitaba bağlı kalırsanız o zaman pek çok şey eksik kalıyor."(ÖE, 8),

\subsection{Türk Kültür Ögelerinin Aktarımında Dil ve Kültür Ögelerine İlişkin Öğretim Elemanı Görüsslerine Yönelik Bulgular}


Tablo 2.4'te öğretim elemanlarının "Türk kültür ögelerinin aktarımında dil ve kültür ögeleri" konusundaki düşüncelerine yer verilmiştir. Bu araştırma sorusuna ilişkin görüşleri aşağıda Tablo 2.4.'te sunulmuştur:

Tablo 2.4. Türk Kültür Ögelerinin Aktarımında Dil ve Kültür Ögelerine İlişkin Öğretim Elemanı Görüşleri

\begin{tabular}{ll}
\hline Görüşler & f \\
\hline Kültür Aktarımı Dil Öğretimini Kolaylaştırır, Artırır & 6 \\
İç içe Geçmiş Durumdadırlar & 4 \\
Dilin Kültürü Şekillendirmesi/ Taşıyıcı Rolü & 2 \\
Birbirini Tamamlayııı Yönü & 1 \\
Vardır &
\end{tabular}

Tablo 2.4.'te görüldüğü gibi Türk kültür ögelerinin aktarımında dil ve kültür ögelerine ilişkin öğretim elemanı görüşlerine yönelik dört farklı kategoriye ulaşılmıştır. Bu kategoriler sıklık değerleri açısından sırasıyla şu şekildedir: "kültür aktarımı dil öğretimini kolaylaştırır, artırır", $(\mathfrak{f}=6)$; "iç içe geçmiş durumdadırlar" ( $\mathrm{f}=4)$; "dilin kültürü şekillendirmesi/ taşıyıcı rolü", $(\mathrm{f}=2)$; "birbirini tamamlayıcı yönü vardır" ( $f=1)$. Bu görüşlerden ( $f=13$ ) bazıları aşağıda yer alan ifadelerle örneklendirilmiştir:

"Yabancı dil/ikinci dil öğrenen kişinin o dile tam olarak yetkin olabilmesi için sadece dilin yapısını bilmesi yeterli değildir. Öğrencinin, o dilin hitap, teşekkür, reddetme, kabul etme, teklif sunma, önerme, övgü sözlerini, atasözlerini, deyimlerini, yeme-içme kültürü, sofra adabı, kötü ya da iyi bir durumla karşılaşıllnca gösterilen mimik hareketleri gibi kullanımları hakkında bilgi sahibi olması gerekir."(ÖE, 1),

" Türk kültür ögeleri ve dil öğretimi arasında önemli bir ilişki vardır. Türk kültür ögeleriyle Türk kültürünün yanı sıra Türkçenin dil bilgisi yapısını ve sözvarlığını öğretmek kolaylaşır."(ÖE, 4),

"Her dil, ait olduğu milletten izler taşır. Selamlaşma, vedalaşma, karşılama gibi durumlarda kullanılan söz varliğı unsurları; günlük hayat içerisindeki olay ve durumlar karşısında kullanılan söz varliğı unsurları vs. bunların hepsi kültürün dilsel varlığın oluşturur. Kültürü şekillendiren en önemli unsur dildir"(ÖE, 10).

\subsection{Türk Kültür Ögelerinin Aktarımına İlişkin Öğretim Elemanlarının Önerilerine Yönelik Bulgular}

Tablo 2.5.'te öğretim elemanlarının “Türk kültür ögelerinin aktarımına ilişkin önerileri” konusundaki düşüncelerine yer verilmiştir. Bu araştırma sorusuna ilişkin görüşleri aşağıda Tablo 2.5.'te sunulmuştur:

Tablo 2.5 Türk Kültür Ögelerinin Aktarımına İlişkin Öğretim Elemanlarının Önerileri

\begin{tabular}{ll}
\hline Görüşler & f \\
\hline Öğretici Kendi Kültürüne Hâkim Olmalı & 5 \\
Öğrenciye Bakış Açısı, Bir Bilinç Kazandırabilmeli & 3 \\
Öğretici Öğrenci Grubunun Kültürüne de Hâkim Olabilmeli & 2 \\
Öğretici Öğrenciye Doğru Rehberlik Edebilmeli & 2 \\
Öğrenciyi Aktif Kılmalı & 2 \\
\hline
\end{tabular}


Öğretici Farklı Kaynaklardan Yararlanmalı

Kitap Çalışmaları Artarak Devam Etmeli

\section{1}

1

Toplam 21

Tablo 2.5.'te görüldüğü üzere Türk kültür ögelerinin aktarımına ilişkin öğretim elemanlarının önerilerine yönelik yedi farklı kategoriye ulaşılmıştır. Bu kategoriler sıklık değerleri açısından sırasıyla şu şekildedir: "öğretici kendi kültürüne hâkim olmalı" , $(f=5)$; "öğrenciye bakış açısı, bir bilinç kazandırabilmeli" , $(f=3)$; "öğretici öğrenci grubunun kültürüne de hâkim olabilmeli", $(f=2)$; "öğretici öğrenciye doğru rehberlik edebilmeli", $(f=2)$; "öğrenciyi aktif kılmalı", $(f=2)$; "öğretici farklı kaynaklardan yararlanmalı", $(f=1)$; ve "kitap çalışmaları artarak devam etmeli", $(f=1)$. Bu görüşlerden bazıları aşağıda yer alan ifadelerle örneklendirilmiştir:

"Mesela; öğretim elemanınin tiyatro, halk oyunlarn bilgisi, enstrümantal alet bilgisi, geleneksel Türk sanatlarından vb. bilgi sahibi olması gerekir. Sadece kuru bir Türkçe öğretimi ya da gramer öğretimi başta öğrenciyi akabinde öğretmeni boğar. Neticede sağhlkl bir eğitim olmaz. Çünkü Türk soylu olan/olmayan öğrenciler Türkçeyi eğlenerek, gezerek, görerek, tekrarlayarak, mukayese ederek, gözlemleyerek vb. şekillerde öğrenmektedir."(ÖE, 1),

“YTÖ'nde öğretmen öğrencinin sürekli iletişimde olduğu kişilerden biridir. Bunun için bu konuda öğretmene önemli görevler düşmektedir. Öğrenciye anlatabildiği kadar doğru bilgiler vermeye çalışmalıdır ve öğrencilerin sorularına cevap bulmaları için onları doğru adreslere yönlendirmelidir."(ÖE, 5),

“Öğretim elemanları dile ve kültüre tam anlamıyla hâkim olmahdır. Ilımlı bir tutum sergilemelidir."(ÖE, 10).

\section{3. İstanbul Yabancılar İçin Türkçe Ders Kitabı Öğrenim Setinde Bulunan Türk Kültür Ögelerine Yönelik Bulgular}

İstanbul Yabancılar için Türkçe Ders Kitabı A1, A2, B1, B2 ve C1+ seviyesi kitaplarındaki Türk kültür ögelerine yönelik bulgulara yer verilmiştir. Bu araştırma sorusuna ilişkin bulgular aşağıda Tablo $3^{\prime}$ te sunulmuştur:

Tablo 3. İstanbul Yabancılar için Türkçe Ders Kitabı A1, A2, B1, B2 ve C1+ Seviyesi Kitabındaki Türk Kültür Ögeleri

\begin{tabular}{|c|c|c|c|c|c|}
\hline \multirow[b]{2}{*}{ KATEGORİLER } & \multicolumn{5}{|c|}{ DİL DÜZEYLERİ } \\
\hline & A1 & A2 & B1 & B2 & $\mathrm{C} 1+$ \\
\hline & $f$ & $f$ & $f$ & $f$ & $f$ \\
\hline Günlük Yaşam & 24 & 40 & 27 & 3 & 15 \\
\hline Yaşam Koşulları & 46 & 30 & 49 & 10 & 18 \\
\hline Kişiler Arası İlişkiler & 34 & 81 & 20 & 22 & 4 \\
\hline Değerler, İnançlar ve Tutumlar & 17 & 47 & 133 & 103 & 166 \\
\hline Beden Dili & 0 & 0 & 8 & 0 & 1 \\
\hline Sosyal Gelenekler & 29 & 33 & 41 & 12 & 16 \\
\hline Geleneksel Davranışlar & 13 & 4 & 2 & 0 & 9 \\
\hline TOPLAM & 163 & 235 & 280 & 150 & 229 \\
\hline
\end{tabular}

\section{Sonuç ve Tartışma}

Bu çalışmada yabancılar Türkçe öğretiminde Türk kültür ögelerinin aktarımı konusunda yabancı öğrencilerin ve öğretim elemanlarının görüşleri bağlamında incelenmesi amaçlanmıştır. Araştırmanın bu bölümünde verilerin analizi sonucunda elde edilen bulgular tartışılarak elde edilen sonuçlara ve önerilere yer verilmiştir. Bu konuda yabancı öğrencilerle yapılan görüşmeler sonucu ortaya çıan bulgular incelendiğinde; Türk Dil Kurumu (TDK, 2020) tarafından bir topluma, ülkeye özgü düşünce ve sanat eserlerinin tümü olarak tanımlanan kültür, araştırmaya katılan öğrenciler tarafından dil, yaşam biçimi, tarih, edebiyat, yeme-içme, davranış biçimi, gelenek-görenek, eylemler ve kurallar olarak 
tanımlanmıştır. Bu bulgular neticesinde yabancı öğrencilerin kültürü en çok yaşam içinde davranış biçimleriyle gözlemledikleri sonucuna ulaşılmıştır.

Yabancı öğrenciler Türk kültür ögelerine ilişkin bilgi kaynaklarını sırasıyla en çoktan aza doğru; sosyal hayat, ders kitapları, arkadaşlar, öğretmenler, kitaplar- dergiler, diziler/ filmler ya da tiyatrolar, videolar, internetler ve geziler şeklinde ifade etmişlerdir. Buna göre yabancı öğrenciler Türk kültür ögelerine ilişkin en fazla bilgiyi sosyal hayattan öğrenmekte olup bunu ders kitapları ve Türk arkadaşlar takip etmektedir.

Yabancı dil olarak Türkçe öğretimi ders kitaplarında yer alan Türk kültür ögeleri hakkında yabancı öğrenciler; şehirler, insan ilişkileri, Türk halk edebiyatı, tarih, tarihi önemli kişiler, mucitler, din, batıl inançlar ve kitaplarının bu ögeler konusunda yetersiz olduğuna dair görüş bildirmişlerdir. Eren Ökten (2013), yaptığı araştırma sonucunda dil sınıflarında kültür aktarımının, dil becerilerini geliştirdiği gibi başka kültürlerin anlaşılabilirliğine de katkı sağladığını ifade edilmiştir

Yabancı öğrencilere Türk kültürüne ait daha fazla bilgi sahibi olmak istedikleri konular sorulduğunda, öğrenciler en çok Türkiye'nin tarihi hakkında bilgi sahibi olmak istediklerini söylemişlerdir. Öğrencilerin tarihten sonra en çok bilgi sahibi olmak istedikleri konu ise Türkiye' nin farklı çevrelerini, yerlerini keşfetmek ve görmek olarak ifade etmişlerdir. Bunu sırasıyla Türk yemekleri, Türkiye'nin gelecekteki konumu, dili ve ekonomisi takip etmektedir. Gökmen (2000), yapmış olduğu araştırma sonucunda kültürlerarası iletişimsel edinç ile birlikte bireylerin kendi kültürleri dişındaki bireylerle iletişim kurmalarının kolaylaşacağını belirtmiştir.

Altundağ (2007), yapmış olduğu araştırma sonucunda, elde edilen veriler doğrultusunda; etkili ve kalıcı bir yabancı dil öğretimi gerçekleştirebilmesi için, öğrencilere o dilin kültürünü sevdirecek ve o kültüre karşı merak uyandıracak, öğrencileri güdüleyecek şekilde eğitim verilmesi gerektiğini öngörmüştür. Yabancı dil olarak Türkçe öğretimi derslerine girmekte olan öğretim elemanlarıyla yapılan görüşmeler sonucu ortaya çıkan bulgular incelendiğinde; birinci alt amaç olarak kültür aktarımı hakkındaki görüşlerine başvurulmuştur. Bu alt amaç doğrultusunda öğretim elemanları kültür aktarımını; gelenekgöreneklerin aktarımı, milli kültür unsurlarının nesilden nesile taşınması, dil öğretiminde olmazsa olmaz unsur, ön yargıları yıkan bir unsur ve farklı kültürlerin kesişmesini sağlayan bir unsur olarak ifade etmişlerdir. Yabancı dil olarak Türkçe öğretimi derslerine girmekte olan öğretim elemanlarına Türk kültür ögelerinin aktarımında kullanılan bilgi kaynakları olarak neler kullandıkları ikinci alt amaç olarak sorulmuştur. Öğretim elemanları bu doğrultuda; video ve ses kayıtlarını, kitapları, görselleri, diziler/ filmleri, diğer eğitim kaynaklarını, sözlükler ve gezileri belirtmişlerdir.

Üçüncü alt amaç olarak yabancı dil olarak Türkçe öğretiminde kullanılan ders kitapları hakkındaki öğretim elemanlarının görüşleri alınmıştır. Buna göre yabancı dil olarak Türkçe öğretimi derslerine girmekte olan öğretim elemanları kullanılmakta olan ders kitaplarının olumlu ve olumsuz yönlerine değinmişlerdir. Yabancılara Türkçe öğretiminde kullanılmakta olan ders kitaplarının olumlu yönleri olarak; İngilizce açıklamalarının da Türkçe açıklamalarla birlikte verilmesi, kültür ile ilgili ünitelerin olması, Türk kültürü ile ilgili örnekleri içermesi ve ünitelerin dengeli dağılmış olması şeklinde ifade etmişlerdir. TÖMER'de görev alan öğretim elemanları Yabancılara Türkçe öğretiminde kullanılmakta olan ders kitaplarının olumsuz yönleri olarak ise; Türk edebiyatı kaynakları bakımından yetersiz olduğu, konu dağılımı ve konulara yer verme miktarının dengeli olmaması, Türk kültür ögelerinin daha detaylı verilebilmesi gerektiği ve diğer sorunlar biçiminde görüşlerini bildirmişlerdir.

Yabancılara Türkçe öğretiminde Türk kültür ögelerinin aktarımında kullanılan strateji, yöntem ve tekniklere ilişkin dördüncü alt amaç olarak öğretim elemanlarının fikirlerine değinilmiştir. Bu amaç etrafında öğretim elemanlarının Yabancılara Türkçe öğretimi derslerinde kullandıkları; yöntemler, teknikler ve stratejilere ilişkin görüşlerini belirtmişlerdir.

Beşinci alt amaç olarak Yabancllara Türkçe öğretiminde görev alan öğretim elemanlarının Türk kültür ögelerimin aktarımını, dil ve kültür ilişkisi açısından değerlendirmeleri istenmiş̧tir. Bu çerçevede; kültür aktarımının dil öğretimini kolaylaştırdığını ve arttırdığını, iç içe geçmiş durumda olduğunu, dilin kültürü şekillendirdiği/ taşıyıcı rolü olduğu ve birbirini tamamlayıcı yönü hakkında görüş bildirmişlerdir. Salazar ve Carballo (2011), yaptıkları araştırma sonucunda aynı şekilde öğretim elemanlarının kültürün ve dilin birbirleri ile ayrılmaz bir bağ olduğunun farkında oldukları ifade 
etmişlerdir. Araştırmanın veri toplama sürecinde son amaç olarak Türk kültür ögelerinin aktarımına ilişkin Yabancılara Türkçe öğretiminde derslere girmekte olan öğretim elemanlarının önerileri ortaya çıkmıştır. Bu alt amaç doğrultusunda öğretim elemanları; öğreticilerin kendi kültürüne hâkim olmasını, öğrenciye bakış açısı/ bir bilinç kazandırabilmelerini, öğreticilerin öğrenci grubunun kültürünü de hâkim olabilmesini, öğreticilerin öğrencilere doğru rehberlik edebilmelerini, öğrencinin aktif kılınmasını, öğreticinin farklı kaynaklardan yararlanmasını ve kitap çalışmalarının artarak devam etmesini önermiştir.

Peterson ve Coltrane, (2003) kültür aktarımı konusunda yaptıkları araştırma çerçevesinde benzer şekilde yabancılara Türkçe öğretmekte olan öğreticilerin, kültür tanıtıcısı rolünde olması gerektiğini ifade etmiştir. Çalışmada öğreticilerin, farklı bir kültürle karşı karşıya kalan öğrencinin kültürü zorla dayatmadan, keşfederek öğrenmesine yol açması gerektiği de belirtilmiştir. Öğrencinin yaşadığı kültürel zorlukların üstesinden gelmesinde gerek rol-model olarak gerekse doğru bir şekilde yönlendirerek yardımcı olunmalıdır. Böylece öğrenci içinde bulunduğu kültürü daha rahat bir şekilde anlayacak ve varsa içinde bulunduğu kültür hakkındaki olumsuz düşüncelerinden kurtulabilecektir.

Atay, Kurt, Çamlıbel, Ersin ve Kaslığlu (2009), yaptıkları araştırma sonucunda öğretmenlerin ikinci dil öğretiminde kültürün rolünün öneminin farkında oldukları saptanmış ancak öğretmenlerin kültürel farkındalık için yeterli çaba harcamadıkları ortaya çıkmıştır.

Er (2015), çalışmanın sonucunda öğretmenler ve müdür yardımcıları Yabancılara Türkçe öğretimi sürecinde kültürel farkındalık oluşturmayı genellikle gerekli bulmakta olduğunu ifade etmiştir. Öğretmenlere göre kültürel farkındalık oluşturma süreci kendilerine iletişim kurma, tecrübe kazanma, hoşgörülü olma gibi konularda katkı sağlamıştır. Ancak sınıf içinde öğretmenlerin kültürel farkındalığa yönelik uygulamalara genellikle yer vermedikleri gözlenmiştir. Araştırmada öğretmenlerin çoğunluğu Yabancılara Türkçe öğretimi sürecinde kültürel farkındalığa yönelik amaçların faydalı olacağını belirtmiştir.

Araştırma kapsamında ele alınan yabancı dil olarak Türkçenin öğretiminde kullanılmakta olan kitapların Türk kültür ögelerinin aktarımı konusunda Avrupa Ortak Çerçeve metni tarafından belirlenen ölçütlere göre kültür aktarımı konusuna yer verdiği ancak verilen Türk kültür ögelerinin içeriğinin yeterli olup olmadığı ve neye göre belirlendiği konusunda bir takım eksiklikler olduğu sonucuna varılmıştır. Araştırma sonucunda, incelenen ders kitaplarının seviyelerinin arttıkça Türk kültür ögeleri açısından daha kapsamlı çok yer verildiği görülmektedir. Benzer şekilde Okur ve Keskin (2013), İstanbul Yabancılar için Türkçe ders kitaplarını incelediği çalışmada; A1 ve A2 temel seviye ders kitaplarında kültür ögelerinden daha az yararlanıldığı, B1 ve B2 orta seviye ders kitaplarında ise kültür ögelerine daha çok faydalanıldığı ifade edilmiştir. Ancak bununla birlikte kültür ögelerinden daha çok yararlanılması gerektiği belirtilmiştir. Yılmaz (2012), yaptığı araştırma sonucunda Yabancılar için Türkçe Yeni Hitit serisi kitaplarını kültürel öge aktarımı açısından yeterli ve başarılı bulmuştur. Açıkgöz (2018) ise, "Yabancı Dil Olarak Türkçe Öğretimi Ders Kitaplarında Kültür Aktarımı: Yeni Hitit Yabancılar İçin Türkçe Ders Kitabı: (A1-A2 Düzeyi)", isimli çalışmanın sonucunda örneklem olarak seçtiği ders kitaplarının kültür aktarımı açısından yeterli sayılabileceğini ancak bazı eksikliklerinin bulunduğunu belirtmiştir. İncelediği ders kitabında, kültür ögelerinin dağılımının dengeli olmadığını ve hedef kültüre, farklı kültürlere yer verilmesine rağmen hedef ve kaynak kültürün karşılaştırılmasına yeterince yer verilmediği sonuçlarına ulaşmıştır.

Yabancılara Türkçe öğretimi ders kitaplarında Türk kültür ögeleri yapılan inceleme sonucunda daha çok "kültürden kültüre" adıyla farklı bir bölümde ve ünite sonlarında yer alan kısa, bilgilendirici metinlerde geçmektedir. Fakat bu Türk kültür ögelerinin ayrı bir bölümde dikte edermişçesine verilmesi yerine kitaplarda yer alan okuma, yazma, konuşma, dinleme gibi diğer becerilerin arasında sezdirilerek verilmesinin daha uygun olacağı düşünülebilir. Bölükbaş ve Keskin (2010), yaptıkları araştırma sonucunda Yabancılara Türkçe öğretimi sürecinde metinlerin işlenişinde; öğrencilerin metinler yoluyla yeni düşünüş biçimleriyle, yaşam tarzlarıyla karşılaşmalarını; kendi kültürleri ile Türk kültürünü karşılaştırarak Türk kültürüne karşı hoşgörülü yaklaşmayı öğrenmelerini sağlayacak etkinliklere yer verilmesi gerektiği ifade etmiştir.

Araştırma sonucunda, göze çarpan bir diğer sonuç için Yabancılara Türkçe öğretimi ders kitaplarında geçen Türk kültür ögelerinden bazılarının çok eski ve bir Türk'ün dâhi kolayca hatırlayamayacağı konulara ve kültür unsurlarına yer verildiği şeklindedir. Ayrıca ders kitaplarında geçen Türk kültür 
ögelerinin bazıları yabancı öğrenciler için, gereksiz ayrıntılara yer verilerek yer aldığından yabancı öğrencilere göre uygun nitelikte olmadığı söylenebilir. Demir ve Açı (2011), yaptıkları araştırmada kitaplarda kültürel ögelerin hangilerinin öncelikli olarak verilmesi ve ne kadar verilmesi gerektiği konusunda bir ölçütün olmadığı sonucuna ulaşmıştır.

Kalfa (2013), yabancılara Türkçe öğretiminde sözlü kültür unsurlarının kullanılmasını araştırdığı çalışmanın sonucunda, dil öğretiminin kültürel etkileşim süreci olduğunu ifade etmiştir. Bununla birlikte, yabancılara Türkçe öğretiminde hazırlanan ders programı, materyal ve kaynaklarda Türk kültürüne yer verilmesi gerektiği ifade edilmiştir. Bahsedilen çalışmaların sonuçları, yapılan bu çalışmanın sonuçlarını destekler niteliktedir

\section{Öneriler}

Araştırmadan elde edilen sonuçlar doğrultusunda yabancılara Türkçe öğretiminde öğrencilere, öğretim elemanlarına, ders kitapları yazarlarına, araştırmacılara ve diğer ilgililere yönelik öneriler aşağıda sunulmuştur:

\section{Uygulamaya Dönük Öneriler}

- Yabancılara Türkçe öğretimi ders kitaplarında Türk kültür ögelerinden daha çok faydalanılabilir. Kitapların seviyesi arttıkça daha çok kültür ögesine yer verilebilir.

- Öğretim elemanları kültür aktarımıla ilgili bilgileri teknolojiyi kullanarak işleyebilir.

- Türkçe'nin yabancılara öğretiminde kullanılan ders kitapları için bir inceleme komisyonu oluşturulabilir. Yine bu komisyonun çatısı altında yapılan çalışmalar takip edilerek derslere girmekte olan öğretim elemanlarına kültürün aktarımı konusunda kurslar açılabilir, eğitimler verilebilir.

- Yabancılara Türkçe öğretimi ders kitaplarında temel kazanımlar olan okuma, yazma, konuşma ve dinleme becerilerinin içine kültür ögeleri doğrudan farklı bölümler içinde değil de sezdirilerek verilebilir.

- Yabancılara Türkçe öğretimi ders kitapları hazırlanırken kültür aktarımı boyutu dolaylı olarak temel becerilerin içerisine kaynaştırılarak verilebilir. Öğrencilerin daha kolay anlayabileceği bir biçimde güncel ve gerçeğe yakın bir biçimde görsellerle ve etkinliklerle desteklenerek aktarılabilir.

- Yabancılara Türkçe öğretimi ders kitaplarında yer alan kültür ögelerinin ayrıca geçmişte kalmış, günümüzde unutulmuş ya da çok fazla bilinmeyen kültürel unsurlar yerine daha güncel günümüzü yansıtan ögelerden oluşmasına dikkat edilmesi düşünülebilir.

İleriye Dönük Araştırmalara İlişkin Öneriler

- Öğretim elemanlarının dil öğretiminde Türk kültür ögelerinin aktarımını daha iyi kavramasına yönelik akademik çalışmaların sayısı arttırılabilir.

- Yabancılara Türkçe öğretiminde Türk kültürünün aktarımına ilişkin yabancı öğrencilere yönelik projeler, etkinlikler yapılabilir.

- Yabancılara Türkçe öğretiminde Türk kültür ögelerinin aktarımına yönelik ders kitabı incelemelerine yönelik çalışmalar bulunmaktadır. Fakat öğrenci, öğretim elemanları, kurum yöneticilerine ve programa dair incelemeler nitelik ve nicelik olarak arttırılabilir.

- Yabancılara Türkçe öğretiminde Türk kültür ögelerinin aktarımına yönelik çalışmalar farklı çalışma grupları oluşturularak, farklı çalışma yöntemleriyle; nitel, nicel ve karma yöntemler kullanılarak yapılabilir.

\section{Kaynakça}

Abacıoğlu, T. (2002). Çocuklara Oyunlarla Yabancı Dil Öğretimi (Yayımlanmamış Yüksek Lisans Tezi). Ankara: Gazi Üniversitesi Eğitim Bilimleri Enstitüsü.

Açıkgöz, E. S. (2018). Yabancı dil olarak Türkçe öğretimi ders kitaplarında kültür aktarımı: Yeni Hitit yabancılar için Türkçe ders kitabı: (A1-A2 Düzeyi), (Yayımlanmamış yüksek lisans tezi).

Gaziosmanpaşa Üniversitesi, Tokat. 
Altundağ, P. (2007). Kültürlerarası yeterlilik ve Korece öğretimi. (Yayımlanmamış Yüksek lisans tezi). Ankara Üniversitesi, Ankara.

AOÇ. (2013). Diller İçin Avrupa Ortak Öneriler Çerçevesi. Öğrenim, Öğretim ve Değerlendirme. (Çev. Nakipoğlu B. , Çıkar M., Genç A., Atalay C. ) Erişim Tarihi: 10 Mayıs 2020 tarihinde http://www.dilbilimi.net/ab_diller_icin_ortak_avrupa_basvuru_metni_meb adresinden alınmıştır.

Arslan, M. (2009). Türkiye'de yabancı dil edinim sorunu ve yabancı dil olarak Türkçe. In 1st International Symposium on Sustainable Development. 9-10.

Asutay, H. (2003). Yabancı dil öğretiminde kültür bağlamı ve öteki dil. Ankara Üniversitesi (TÖMER) Dil Dergisi, S, 118, 26-29.

Asutay, H. (2007). Türk dili derslerinde çocuk ve gençlik yazını. Adana: Çukurova Üniversitesi Türkoloji Araştırma Merkezi.

Atay, D., Kurt, G., Çamlıbel, Z., Ersin, P. ve Kaslığlu, Ö. (2009). The role of intercultural competence in foreign language teaching. Inonu University Journal of The Faculty of Education, 10 (3), 123135.

Barın, E. (2004). Yabancılara Türkçe öğretiminde ilkeler. Hacettepe Üniversitesi Türkiyat Araştırmaları (HÜTAD), (1), 19-30.

Bölükbaş, F. ve Keskin, F. (2010). Yabancı dil olarak Türkçe öğretiminde metinlerin kültür aktarımındaki işlevi. Turkish Studies, 5 (4), 221-235.

Christensen, L. B., Johnson, B. and Turner, L. A. (2011). Research methods, design, and analysis. Boston: Allyn and Bacon.

Çağlayan-Dilber, N. (2018). Yabancılara Türkçe öğretimi üzerine yazılan kaynak kitaplara ilişkin bir inceleme. Uludağ Üniversitesi Ĕ̆itim Fakültesi Dergisi 31 (Özel Sayı), 111-128.

Demir, A. ve Açık, F. (2011). Türkçenin yabancı dil olarak öğretiminde kültürlerarası yaklaşım ve seçilecek metinlerde bulunması gereken özellikler. TÜBAR, 30, 51-72.

Demir, A. ve Açı, F. (2011). Türkçenin yabancı dil olarak öğretiminde kültürlerarası yaklaşım ve seçilecek metinlerde bulunması gereken özellikler. TÜBAR, 30, 51-72.

Demirel, M.V. (2011). Türkçe üçüncü sınıf öğrencilerinin yabancılara Türkçe öğretimi dersine ilişkin görüşleri. Buca Eğitim Fakültesi Dergisi, 31, 128-138.

Er, K. O. (2006). Yabancı dil öğretim programlarında kültürün etkileri. Ankara Üniversitesi Eğitim Bilimleri Fakültesi Dergisi, 39(1), 1-14.

Er, O. (2015). Yabancılara Türkçe öğretimi uygulamalarının kültürel farkındalık oluşturma açısından incelenmesi (Yayımlanmamış doktora tezi). Atatürk Üniversitesi Eğitim Bilimleri Enstitüsü, Erzurum.

Erdem, M. D., Gün, M., ve Sever, P. (2015). Türkçenin yabancı dil olarak öğretiminde yöntem seçimi ve alternatif yöntemler. Electronic Turkish Studies, 10(11).

Eren Ökten, C. (2013). Teaching foreign language with using cultural aspects of literature. Sosyoloji Dergisi, 3 (26), 33-43.

Gay, G. (2014). Kültürel değerlere duyarlı eğitim: Teori, araştırma ve uygulama. Ankara: Anı Yayıncılık.

Göçer, A. ( 2015 ).Türkçenin Yabancı dil olarak öğretiminde konuşma becerisinin kazandırılması. Trakya Üniversitesi Sosyal Bilimler Dergisi, 17 (2), 21-36.

Gökmen, M. E. (2000). Yabancı dil öğretiminde kültürlerarası iletişimsel edinç. Dil Dergisi, 128, 69-78.

Güvenç, B. (2002a). İnsan ve Kültür. İstanbul: Remzi Kitabevi.

Harputoğlu, B. (2015). Yabancı dil olarak Türkçe ve ana dil Türkçe ders kitaplarında öğrenme stratejilerinin incelenmesi. (Yayımlanmamış Yüksek Lisans Tezi). İstanbul Üniversitesi, İstanbul.

Hengirmen, M. (1993). Türkçenin yabancı dil olarak öğretimi. (TÖMER) Dil Dergisi 10, 5-9.

İşcan, A. (2011). Türkçenin yabancı dil olarak önemi. Uluslararası Avrasya Sosyal Bilimler Dergisi, 2(4), 29-36.

İşcan, A. Ve Yassıtaş, T. (2018). Yabancı dil olarak Türkçe öğretimi ders kitaplarında kültür aktarımı: Yedi İklim Türkçe öğretim seti örneği (B1-B2 Düzeyi). Aydın Tömer Dil Dergisi, 3(1), 47-66.

Kalfa, M. (2013). Yabancılara Türkçe öğretiminde sözlü kültür unsurlarının kullanımı. Millî Folklor, 97, 167-177.

Karababa, C. (2009). Yabancı dil olarak Türkçenin öğretimi ve karşılaşılan sorunlar. Ankara Üniversitesi Ĕ̆itim Bilimleri Fakültesi Dergisi, 42 (2), 265-277.

Kırkkılıç, A. ve Sevim, O. (2012). Yabancı dil olarak Türkçe öğretimi (2. Baskı). Ankara: Pegem Akademi. Kramsch, C. (f=1993). Contextand culture in language teaching, Oxford: Oxford University. 
Kurt B., Direkci B. ve Caner M. (2018). Yabancı dil olarak Türkçe öğretimine ilişkin İngilizce öğretmeni adaylarının görüşleri. Turkısh Studies, 13, 1017-1037.

Kuşçu, S. (2013). Türkçenin yabancı dil olarak öğretiminde öğretmen bilişi ve öğrenci inanışları, (Yayımlanmamış yüksek lisans tezi). Ankara Üniversitesi Sosyal Bilimler Enstitüsü, Ankara.

Kutlu, A. (2015). "Yabancılara Türkçe öğretiminde kültürün araç olarak kullanımı: Gazi yabancılar için Türkçe öğretim seti örneği (B1- B2 seviyesi)". K.Ü. Kastamonu Ĕ̆itim Dergisi, 23 (2), 697710.

McMillan, J. H. and Schumacher, S. (2006). Research in education: Evidence-based inquiry. Pearson Higher Ed.

Memiş, M. R. (2016). Yabancı dil öğretiminde eğitim ortamı ve kültür aktarımı. Turkish Studies, 11(9), 605-616.

Mete, F. ve Gürsoy, Ü. (2013). Yabanc1 dil olarak Türkçe öğretiminde öğretmen yeterliklerine ilişkin görüşler. Hacettepe Üniversitesi Ĕ̆itim Fakültesi Dergisi, 28 (3), 343-356.

Okatan, H. İ. (2012). Polis akademisi güvenlik bilimleri fakültesinde okuyan yabancı uyruklu öğrencilerin Türkçe öğrenme sorunları. Polis Bilimleri Dergisi, 14(4), 79-112.

Okur, A. ve Keskin, F. (2013). Yabancılara Türkçe öğretiminde kültürel ögelerin aktarımı: İstanbul yabancılar için Türkçe öğretim seti örneği. The Journal of Academic Social Science Studies, 6 (2), 1619-1640.

Özdemir, C. ( 2013). Dil-kültür ilişkisi: Folklor ürünlerinin Türkçenin yabancı dil olarak öğretiminde yeri ve işlevi, Millî Folklor, 25(97), 157-166.

Pai, Y., Adler, S.A. \& Shaidow, L.K. (2006). Cultural foundations of education (4th ed.). Upper Saddle River, NJ: Merrill/ Prentice Hall. Palardy, J. (1969). What teachers believe- What students achieve. Elemantary School Journal, 69 (7), 370-374.

Peterson, E. and Coltrane, B. (December, 2003). Culture in second language teaching.

Polat, T. (1990). Kültürlerarası bildirişimde etkin bir süreç yabancı dilde okuma-anlama. Alman Dili ve Edebiyatı Dergisi, 7, 69-90.

Salazar, E. Z. and Carballo, O. C. (2011). Teaching culture in the foreign language classroom: A reflective model. Revista de Lenguas Modernas, 14, 283-303.

Saygıllı, D, Kana, F. ( 2018 ). Yabancı dil olarak Türkçe öğreten öğretmenlerin kültürlerarası duyarlılığı. Ana Dili Eğitimi Dergisi, 6 (4), 1041-1063.

Şahin, A. (2018). Yabancı dil olarak Türkçe öğretimi: Kuramlar, yaklaşımlar, etkinlikler. Ankara: Pegem Akademi.

Tapan, N. (1990). Yabancı dil olarak Almanca öğretiminde kültür bağlamının değerlendirilmesi. İstanbul Üniversitesi Alman Dili ve Edebiyatı Dergisi, 7, 55-68.

Tezcan, N. (1990). Türkçenin yabancı dil olarak öğretimi. Çağdaş Türk Dili, 3 (34), 1055-1063.

Tosun, C. (2005). Türkçenin yabanc1 dil olarak öğretilmesi. Journal of Language and Linguistic Studies, $1(1), 22-28$.

Türk Dil Kurumu. (2020). Güncel Türkçe sözlük http://sozluk.gov.tr/ adresinden 21 Nisan 2020 tarihinde alınmıştır.

Yaylı, D. ve Yaylı, D. (2014). Yabancı dil öğretimi yaklaşımları ve yöntemleri. D. Yaylı ve Y. Bayyurt (Ed.), Yabancılara Türkçe öğretimi: politika, yöntem ve beceriler. Ankara: Anı Yayıncılık.

Yıldırım, A. ve Şimşek, H. (2016). Sosyal bilimlerde nitel araştırma yöntemleri. Ankara: Seçkin Yayıncılık.

Yilmaz, F. (2012). Cultural transmission through teaching Turkish as a foreign language course books. Journal of Turkish Studies, 7(3), 2751-2759.

Yin, R. (1984). Case study research: Design and methods. Beverly Hills, CA: Sage Publishing.

\section{Geniş Özet}

Günümüzde yabancı dil olarak Türkçe öğretimi, çeşitli ülkelerdeki insanların değişik ihtiyaç ya da sebeplerle Türkiye'ye gelmesi sonucunda birçok farklı kurumda yapılmakta ve bu kurumlarda öğrenim gören yabancı öğrencilerin sayısının her geçen gün arttığı bilinmektedir. Bu durum Türkçeyi, yabancıların öğrendikleri bir dil hâline getirirken aynı zamanda da Türkçenin yabancı dil olarak öğretiminin de önemini ortaya koymaktadır. Yabancı dil olarak Türkçe öğretiminde doğru ve etkili bir dil öğretiminin gerçekleştirilebilmesi için aynı zamanda toplumun kültürünün de yansttılabilmesi gerekli görülmektedir. Dil aracilığıyla kültür öğretiminin gerçekleşmesi, bireyin o yabancı dilin konuşulduğu ülkede olması durumunda daha da kolaylaşır. Bu doğrultuda araştırma, nitel 
araştırma yöntemlerinden durum çalışmasına göre desenlenmiştir. Nitel araştırma yöntemine uygun olarak doküman analizi, odak grup görüşmesi ve bireysel görüşmeler ile veriler elde edilmiştir. Yabancı dil olarak Türkçe öğretiminde, kültür ögelerinin aktarımının öneminden yola çııılarak ilk olarak Akdeniz Üniversitesi Türkçe Öğretimi Uygulama ve Araştırma Merkezinde kullanılmakta olan yabancılara Türkçe öğretimi ders kitaplarında bulunan Türk kültürüne ait ögeler belirli ölçütlere göre incelenmiştir. Ders kitaplarında tespit edilen Türk kültür ögelerinden hareketle yine Akdeniz Üniversitesi Türkçe Öğretimi Uygulama ve Araştırma Merkezinde öğrenim gören yabancı öğrencilerin Türk kültürü hakkındaki görüşlerine başvurulmuştur. Çalışmanın bir diğer veri toplama aracını ise yine Akdeniz Üniversitesi Türkçe Öğretimi Uygulama ve Araştırma Merkezinde görevli olan öğretim elemanlarıyla gerçekleştirilen bireysel yarı yapılandırılmış görüşmeler oluşturmaktadır. Bu çerçevede 32 yabancı öğrenciyle odak grup görüşmesi, 11 yabancı öğrenci ve 10 öğretim elemanı ile yarı yapılandırılmış bireysel görüşmeler gerçekleştirilmiştir. Verilerin analizi, içerik analizi yoluyla yapılmıştır. Araştırmanın sonucunda yabancı öğrenciler Türk kültür ögelerini daha çok sosyal hayat, Türk arkadaşlar ve dizilerden öğrendiklerini bununla beraber ders kitaplarından ve öğretim elemanlarından da bu konuda yararlandıklarını ifade etmişlerdir. Ayrıca ders kitaplarında da Türk kültür ögelerinin yer aldığı fakat daha güncel ve yabancı öğrencilerin ilgi ve ihtiyaçlarına yönelik kültür ögelerinin yer alması gerektiği sonucuna ulaşılmıştır. TÖMER'de derslere girmekte olan öğretim elemanlarının görüşlerine bakıldığında ise öğretim elemanları; kültür aktarımının yabancı dil öğretiminde olması gereken, en temel unsurlardan biri olarak görmekle birlikte ders kitaplarını Türk kültür ögelerinin öğretimi açısından tam olarak yeterli bulmadıklarını belirtmişlerdir.

Anahtar Kelimeler: Yabancı dil öğretimi, Yabancı dil olarak Türkçe öğretimi, dil ve kültür ilişkisi, kültürel etkileşim, kültür aktarım.

\section{EXAMINATION OF THE STUDENTS AND LECTURERS' VIEWS AND COURSE BOOKS ON THE TRANSFERENCE OF TURKISH CULTURAL ELEMENTS IN TURKISH LANGUAGE TEACHING}

\section{Extended Summary}

Today, teaching Turkish as a foreign language is carried out in many different institutions as a result of people coming to Turkey due to different needs or reasons and it is known that the number of these foreign students increases day by day. This situation makes Turkish a language that foreigners learn and also shows the importance of teaching Turkish as a foreign language. In order to realize correct and effective language teaching in teaching Turkish as a foreign language, reflecting the culture of the society is also necessary. Therefore, the realization of cultural teaching becomes easier if the individual is in the country where the foreign language is spoken. In this context, the research was designed according to the case study, one of the qualitative research methods. Data were obtained through document analysis, focus group interview and individual interviews in accordance with qualitative research methodology. Considering the importance of transfer of cultural elements in teaching Turkish as a foreign language, the elements of Turkish culture in the Turkish textbook for foreigners used in Akdeniz University Turkish Teaching Application and Research Center were examined and evaluated according to certain criteria of the research. Based on the Turkish cultural elements identified in the textbooks, the opinions of foreign students studying at the Turkish Language Teaching Application and Research Center of Akdeniz University about Turkish culture were collected. As another data collection tool of the study, the individual semi-structured interviews were conducted with the lecturers who are working at Turkish Language Teaching Application and Research Center of Akdeniz University. In this context, focus group interviews with 32 foreign students, individual interviews with 11 foreign students and 10 lecturers were conducted through semi-structured interview forms. The collected data analyzed through content analysis. As a result of the research, foreign students stated that they learned Turkish cultural elements mostly from "social life, Turkish friends and soap operas". Besides these, they could also benefit from "textbooks and lecturers". In addition, it is concluded that there are Turkish cultural elements in the textbooks, but cultural elements should be included for students' interests and needs and they should be more up to date elements. In line with the opinions of the lecturers in TÖMER, the lecturers; stated that they did not find the textbooks fully sufficient in terms of Turkish cultural elements, although they considered cultural transfer as one of the most fundamental elements that should be in foreign language teaching.

Keywords: Foreign language teaching, Turkish teaching as a foreign language, language and culture relationship, cultural interaction, culture transfer. 